\title{
Physical activity and quality of life after radical prostatectomy
}

\author{
Daniel Santa Mina, MSc, ; Andrew G. Matthew, PhD, CPsych; ${ }^{*}$ John Trachtenberg, MD, FACS, FRCSC; ; George \\ Tomlinson, PhD; ${ }^{\dagger}$ Crissa L. Guglietti, MSc, ${ }_{r}^{\neq}$Shabbir M.H. Alibhai, MD, MSc; ${ }^{\dagger}$ Paul Ritvo, PhD, CPsych ${ }^{\S}$
}

See related article on page 187.

\section{Abstract}

Background: There are significant post-surgical reductions in healthrelated quality of life (HRQOL) in prostate cancer (PCa) patients undergoing radical prostatectomy (RP). Physical activity (PA) interventions have improved treatment outcomes for PCa patients undergoing radiation and hormone therapy, but PA effects have not previously been examined in the RP setting. This study examined the relationship between preoperative PA levels and postoperative HRQOL outcomes in PCa patients treated with RP.

Methods: Sixty patients were interviewed regarding lifetime PA and completed preoperative (2 weeks prior to surgery) and postoperative (4 weeks after surgery) HRQOL questionnaires. Aerobic fitness testing was conducted on a subsample of 22 patients.

Results: Higher levels of total past-year PA and occupational PA significantly correlated with lesser HRQOL declines from presurgery to 4 weeks post-surgery (Beta $=-0.364, p=0.037$ and Beta $=-0.243, p=0.089$, respectively) in models adjusted for age, postoperative questionnaire completion date, Gleason score and education. Past-year occupational PA was highly positively correlated with past-year total PA $(r=0.785, p<0.001)$. Lifetime total PA was correlated with estimated $\mathrm{VO}_{2} \max (r=0.486$, $p=0.026)$ in the 22 patients who were aerobically tested. Lifetime and past-year PA volumes were not correlated with waist circumference or body mass index.

Interpretation: Declines in HRQOL after RP may be reduced in patients with higher preoperative levels of self-reported PA. These findings require further study with larger samples to confirm results. If confirmed, findings suggest exercise preoperatively may improve HRQOL outcomes after RP.

\section{Résumé}

Contexte : Des réductions post-chirurgicales significatives dans la qualité de vie liée à la santé (QdVS) sont notées chez les patients atteints d'un cancer de la prostate ayant subi une prostatectomie radicale (PR). La pratique d'activités physiques a amélioré les résultats du traitement chez les patients suivant une radiothérapie et un traitement hormonal, mais les effets de l'activité physique n'ont jamais été mesurés en lien avec une PR. La présente étude a examiné le lien entre les niveaux d'activité physique avant l'opération et les scores de QdVS après l'opération chez des patients atteints de cancer de la prostate ayant subi une PR.
Méthodologie : Soixante patients ont été interviewés concernant leur niveau d'activité physique à vie et ont rempli des questionnaires de QdVS 2 semaines avant et 4 semaines après l'intervention chirurgicale. On a mesuré la capacité aérobique chez un sous-groupe de 22 patients.

Résultats : Des niveaux plus élevés d'activité physique totale pendant l'année précédente et d'activité physique au travail étaient significativement corrélés à une baisse moins importante du score de QdVS entre la période précédant l'intervention et la mesure effectuée 4 semaines après l'intervention (bêta $=-0,364, p=0,037$ et bêta $=-0,243, p=0,089$, respectivement) dans des modèles corrigés pour tenir compte de l'âge, de la date où le questionnaire postopératoire a été rempli, du score de Gleason et du niveau d'éducation. Le niveau d'activité physique au travail de l'année précédente était corrélé de façon nettement positive avec le niveau d'activité physique total de l'année précédente $(r=0,85, p<0,001)$. L'activité physique totale à vie était corrélée avec la valeur estimée de consommation maximale d'oxygène $(r=0,486, p=0,026)$ chez les 22 patients dont la capacité aérobique avait été évaluée. Aucune corrélation n'a été notée entre le niveau d'activité physique à vie et au cours de l'année précédente d'une part et la circonférence de la taille ou l'indice de masse corporelle d'autre part.

Interprétation : Le déclin de la qualité de vie liée à la santé après une PR pourrait être réduit chez les patients dont le niveau d'activité physique avant l'opération est plus élevé, selon l'évaluation des patients. Ces résultats doivent être confirmés à l'aide d'études portant sur de plus grandes populations de patients. Une confirmation de ces résultats signifierait que la pratique d'activités physiques avant l'intervention chirurgicale pourrait améliorer les scores de QdVS après une PR.

Can Urol Assoc J 2010;4(3):180-6

\section{Introduction}

Prostate cancer (PCa) is the most common non-skin cancer diagnosis in North American men. ${ }^{1,2}$ Rising incidence rates have been partially attributed to high-fat diets and low physical activity (PA) levels. ${ }^{3}$ Radical prostatectomy $(\mathrm{RP})$, a primary treatment for early stage, localized PCa, is associated with 10-year survival rates of about $90 \%{ }^{4,5}$ However, RP side-effects include urinary incontinence, erectile dysfunction, fatigue, pain, and reduced physical func- 
tioning. Collectively, these side effects negatively affect health-related quality of life (HRQOL) for 6 to 12 months after surgery or longer. ${ }^{6}$ Treatment-related HRQOL deficits have been reduced in PCa patients treated with radiation therapy and androgen ablation with exercise interventions..$^{7-10}$ However, the effect of PA, exercise and physical fitness on HRQOL has never previously been examined in RP patients. The effect of physical fitness on urinary symptoms is also poorly understood in RP patients.

In addition to the positive PA effects reviewed above, higher preoperative PA and exercise levels have been associated with fewer postoperative complications, shorter postoperative hospitalizations, reduced disability and improved HRQOL in abdominal and cardiac surgery patients. ${ }^{11}$

The primary objective of this study was to assess associations between preoperative PA in patients undergoing RP with post-surgical recovery of HRQOL and urinary symptoms. Positive associations could suggest post-surgical HRQOL benefits from interventions designed to increase $\mathrm{PA}$ and fitness prior to surgery.

\section{Methods}

\section{Participants}

Institutional research ethics board approval was obtained prior to participant recruitment. Sixty PCa patients electing retropubic RP for primary treatment of PCa in Toronto, Ontario, were recruited over a period of 12 months. Patients were included if they were 40 to 70 years old, fluent in English, with localized PCa and with no known cognitive impairment. Participants were excluded from the study if they had adjuvant or neoadjuvant PCa treatment (e.g., radiation or hormonal therapy). Participants were specifically excluded from aerobic fitness testing if they had a history of cardiovascular disease, current musculoskeletal injury or if they were currently taking antihypertensive medications.

\section{Measures}

\section{Lifetime Total Physical Activity Questionnaire}

The Lifetime Total Physical Activity Questionnaire (LTPAQ) is an interviewer-administered questionnaire that measures lifetime PA, including occupational, household and recreational activities using cognitive interviewing methods. ${ }^{12}$ Participants described physical activities over their lifetimes and each activity was assigned a metabolic equivalent (MET) value $^{13}$ that, when tallied, yielded total lifetime PA expressed in MET-hours per week (MET-hrs/wk). Past-year total PA was calculated as the weekly average of PA over the past year (12 months prior to date of baseline assessment). The
LTPAQ has demonstrated high intra-rater reliability with significant correlations for hours per week in lifetime PA (0.74), lifetime occupational activity (0.87), household activity $(0.77)$ and recreational activities $(0.72) .{ }^{12}$ The LTPAQ, however, has not been directly validated against objective measures of physical fitness or body composition.

\section{Body composition assessment}

Height and weight were measured 1 to 2 weeks before surgery by a clinic nurse. Waist circumference was assessed during the baseline assessment, according to the protocol defined in the Canadian Physical Activity and Lifestyle Approach. ${ }^{14}$

\section{Modified Canadian Aerobic Fitness Test}

The modified Canadian Aerobic Fitness Test is a submaximal step test that uses the heart rate response to exertion to estimate aerobic fitness $\left(\mathrm{VO}_{2}\right.$ max in $\left.\mathrm{mlO}_{2} / \mathrm{kg} / \mathrm{min}\right) .{ }^{15}$ This test has been validated in a sample of men and women, aged 15 to 69 years and has a strong relationship with directly measured $\mathrm{VO}_{2} \max (r=0.88$, standard error mean $=37.0) .{ }^{15,16}$

\section{Patient-Oriented Prostate Utility Scale}

The Patient-Oriented Prostate Utility Scale (PORPUS) measures disease-specific HRQOL across 10 domains pertinent to PCa patients. ${ }^{17}$ The psychometric scale (used in this study) is disease-specific, brief and comprehensive in assessing PCa related HRQOL domains. The psychometric instrument demonstrated a test-retest reliability of 0.79 to $0.81 .^{18}$ Evidence of strong construct validity has been demonstrated through comparisons with other global psychometric measurements of HRQOL and health status, and modest correlations with utility-based measures of global health status. ${ }^{18}$

\section{International Prostate Symptom Score}

The International Prostate Symptom Score (IPSS) is a brief measure assessing urinary frequency, nocturia, weak urinary stream, hesitancy, intermittence, incomplete emptying and urinary urgency. ${ }^{19}$ This instrument has demonstrated strong test-retest reliability $(r=0.87)$, internal consistency $($ Cronbach's alpha $=0.85)$ and inter-rater reliability. ${ }^{19,20}$

\section{Procedure}

Eligible patients were approached in clinic and they consented to participating in this study at that time. Participants were then scheduled to attend a baseline interview session 1 to 2 weeks before surgery when the LTPAQ, IPSS, PORPUS, aerobic fitness test and waist circumference meas- 
Santa Mina et al.

urements were administered. At the baseline assessment, participants were given a second set of questionnaires (IPSS and PORPUS) to complete 4 weeks after surgery. These questionnaires were returned at their first postoperative appointment with their surgeon.

\section{Statistical analysis}

To assess the impact of PA, body composition and aerobic fitness on HRQOL and urinary symptoms, a "change-score" approach was selected and the change-score was calculated by subtracting baseline scores from postoperative scores for each outcome measure. Higher values indicated greater post-surgical disruption in HRQOL and urinary symptoms.

Descriptive statistics were conducted on all demographic variables, disease information, independent variables and outcome measures. Paired $t$-tests were conducted for HRQOL and urinary symptoms to assess change from baseline to post-surgery. To assess the validity of the LTPAQ, we conducted Pearson correlations with $\mathrm{VO}_{2}$ max, body mass index

Table 1. Demographic and disease-specific information of participants

\begin{tabular}{|c|c|c|}
\hline Variable & Mean & SD \\
\hline \multirow[t]{2}{*}{ Age, yrs } & 60.7 & 5.6 \\
\hline & $\mathbf{n}$ & $\%$ \\
\hline \multicolumn{3}{|l|}{ Ethnicity } \\
\hline Caucasian & 31 & 52.6 \\
\hline Afro-Caribbean & 5 & 8.3 \\
\hline Asian & 2 & 3.3 \\
\hline Hispanic & 1 & 1.6 \\
\hline Did not report & 21 & 35.0 \\
\hline \multicolumn{3}{|l|}{ Education } \\
\hline Undergraduate/post-graduate degree & 28 & 46.7 \\
\hline Completed college/trade school & 16 & 26.7 \\
\hline Completed high school & 6 & 10.0 \\
\hline Did not complete high school & 5 & 8.3 \\
\hline Other & 2 & 3.3 \\
\hline Did not report & 3 & 5 \\
\hline \multicolumn{3}{|l|}{ Marital Status } \\
\hline Married & 42 & 70.0 \\
\hline Single & 7 & 11.7 \\
\hline Divorced/widowed/separated & 6 & 10.0 \\
\hline Did not report & 5 & 8.3 \\
\hline \multicolumn{3}{|l|}{ Gleason } \\
\hline 6 & 30 & 50.0 \\
\hline $7+$ & 29 & 48.3 \\
\hline Information not available & 1 & 1.7 \\
\hline \multicolumn{3}{|l|}{ Stage } \\
\hline T1C & 43 & 71.7 \\
\hline $\mathrm{T} 2 \mathrm{~A}$ & 12 & 20.0 \\
\hline $\mathrm{T} 2 \mathrm{~B}$ & 2 & 3.3 \\
\hline Information not available & 3 & 5.0 \\
\hline
\end{tabular}

\begin{tabular}{lcc}
$\begin{array}{l}\text { Table 2. Physician activity: descriptive statistics for body } \\
\text { composition, PA volume (total and stratified by type), and } \\
\text { aerobic fitness }\end{array}$ & $\mathbf{n}$ & Mean (SD) \\
\hline & 60 & $27.7(3.4)$ \\
\hline BMI (kg/m²) & 39 & $97.2(10.0)$ \\
\hline WC (cm) & 60 & \\
\hline Lifetime PA (MET-hrs/wk) & & $59.4(53.0)$ \\
Occupational PA & & $13.2(4.6)$ \\
Household PA & & $98.4(20.2)$ \\
Recreational PA/Exercise & & \\
Total & 60 & $50.0(64.4)$ \\
\hline Past-year PA (MET-hrs/wk) & & $13.2(11.6)$ \\
$\quad$ Occupational PA & & $22.4(43.3)$ \\
Household PA & & $94.0(77.5)$ \\
Recreational PA/Exercise & & $33.8(4.6)$ \\
Total & 22 & \\
\hline VO max (mIO/kg/min) & & \\
\hline
\end{tabular}

$\mathrm{PA}=$ physician activity $; \mathrm{BMI}=$ body mass index $; \mathrm{WC}=$ waist circumference $\mathrm{SD}=$ standard deviation; $\mathrm{MET}=$ metabolic equivalent tasks.

(BMI) and waist circumference.

A hierarchical multiple linear regression (similar variables are entered in blocks) was conducted to examine the relative contributions of each independent variable on the variance in pre-to-post surgery change scores in HRQOL and urinary symptoms. The alpha level was set at 0.1 for the multivariate analysis to compensate for the small sample sizes and to facilitate detection of statistical trends. Regression models controlled for age, education, Gleason score and time from RP to completion of final questionnaire. Waist circumference and BMI were interchanged in each model to avoid multicollinearity (variance inflation factor: $\mathrm{BMI}=4.656$, waist circumference $=4.473, r=0.860$, $p<0.001)$.

\section{Results}

Eighty-seven patients were approached and 60 (69\%) agreed to participate. Of the 27 who refused participation, 7 did not provide a reason, 10 simply did not want to participate and 10 chose a treatment course other than RP at the study

\begin{tabular}{|c|c|c|c|c|}
\hline Measure & Baseline* & Postoperative* & Change & Significance \\
\hline $\begin{array}{l}\text { Urinary } \\
\text { symptoms } \\
\text { (IPSS) }\end{array}$ & $9.2(7.5)$ & $14.0(7.7)$ & $\begin{array}{c}4.5 \\
(8.9)\end{array}$ & $p<0.001$ \\
\hline $\begin{array}{l}\text { HRQOL } \\
\text { (PORPUS) }\end{array}$ & $17.6(13.0)$ & $42.1(15.2)$ & $\begin{array}{c}24.1 \\
(16.0)\end{array}$ & $p<0.001$ \\
\hline \multicolumn{5}{|c|}{$\begin{array}{l}\text { * = Mean baseline and postoperative scores }(\mathrm{SD})(\mathrm{n}=60) ; \mathrm{HRQOL}=\text { health-related quality } \\
\text { of life; SD = standard deviation; IPSS - International Prostate Symptom Score; } \\
\text { PORPUS = Patient-Oriented Prostate Utility Scale. }\end{array}$} \\
\hline
\end{tabular}




\begin{tabular}{|c|c|c|c|c|c|c|c|c|c|c|}
\hline & BMI & wC & $\begin{array}{c}\text { Lifetime } \\
\text { HH }\end{array}$ & $\begin{array}{l}\text { Lifetime } \\
\text { Occ }\end{array}$ & $\begin{array}{l}\text { Lifetime } \\
\text { Rec }\end{array}$ & $\begin{array}{l}\text { Lifetime } \\
\text { Total }\end{array}$ & $\begin{array}{c}\text { Past-year } \\
\text { HH }\end{array}$ & $\begin{array}{l}\text { Past-year } \\
\text { Occ }\end{array}$ & $\begin{array}{c}\text { Past-year } \\
\text { Rec }\end{array}$ & $\begin{array}{c}\text { Past-year, } \\
\text { total }\end{array}$ \\
\hline $\begin{array}{l}\mathrm{VO}_{2} \\
\max \end{array}$ & $\begin{array}{c}-0.562 \\
0.006^{* *}\end{array}$ & $\begin{array}{l}-0.483 \\
0.027^{*}\end{array}$ & $\begin{array}{l}0.230 \\
0.316\end{array}$ & $\begin{array}{l}0.284 \\
0.212\end{array}$ & $\begin{array}{l}0.365 \\
0.104\end{array}$ & $\begin{array}{c}0.486 \\
0.026^{*}\end{array}$ & $\begin{array}{l}0.139 \\
0.547\end{array}$ & $\begin{array}{l}0.088 \\
0.705\end{array}$ & $\begin{array}{l}0.327 \\
0.148\end{array}$ & $\begin{array}{l}0.369 \\
0.155\end{array}$ \\
\hline BMI & & $\begin{array}{c}0.860 \\
0.000^{*}\end{array}$ & $\begin{array}{l}-0.085 \\
0.520\end{array}$ & $\begin{array}{l}0.128 \\
0.331\end{array}$ & $\begin{array}{l}-0.133 \\
0.310\end{array}$ & $\begin{array}{l}0.039 \\
0.765\end{array}$ & $\begin{array}{l}0.123 \\
0.349\end{array}$ & $\begin{array}{l}0.050 \\
0.704\end{array}$ & $\begin{array}{l}0.054 \\
0.682\end{array}$ & $\begin{array}{l}0.076 \\
0.562\end{array}$ \\
\hline $\begin{array}{c}\text { Waist } \\
\text { circumference }\end{array}$ & & & $\begin{array}{l}0.000 \\
0.998\end{array}$ & $\begin{array}{l}0.157 \\
0.341\end{array}$ & $\begin{array}{l}-0.181 \\
0.269\end{array}$ & $\begin{array}{l}0.060 \\
0.715\end{array}$ & $\begin{array}{l}0.049 \\
0.767\end{array}$ & $\begin{array}{l}0.211 \\
0.198\end{array}$ & $\begin{array}{l}-0.115 \\
0.484\end{array}$ & $\begin{array}{l}0.136 \\
0.410\end{array}$ \\
\hline $\begin{array}{c}\text { Lifetime } \\
\mathrm{HH}\end{array}$ & & & & $\begin{array}{l}0.023 \\
0.861\end{array}$ & $\begin{array}{l}-0.21 \\
0.101\end{array}$ & $\begin{array}{l}0.144 \\
0.273\end{array}$ & $\begin{array}{c}0.538 \\
<0.001 * *\end{array}$ & $\begin{array}{l}0.178 \\
0.174\end{array}$ & $\begin{array}{l}-0.201 \\
0.124\end{array}$ & $\begin{array}{l}0.229 \\
0.078\end{array}$ \\
\hline $\begin{array}{l}\text { Lifetime } \\
\text { Occ }\end{array}$ & & & & & $\begin{array}{l}-0.122 \\
0.35\end{array}$ & $\begin{array}{c}0.888 \\
<0.001 * *\end{array}$ & $\begin{array}{l}0.034 \\
0.797\end{array}$ & $\begin{array}{c}0.730 \\
<0.001 * *\end{array}$ & $\begin{array}{l}-0.092 \\
0.484\end{array}$ & $\begin{array}{c}0.578 \\
<0.001 * *\end{array}$ \\
\hline $\begin{array}{l}\text { Lifetime } \\
\text { Rec }\end{array}$ & & & & & & $\begin{array}{c}0.276 \\
0.033^{*}\end{array}$ & $\begin{array}{l}-0.048 \\
0.714\end{array}$ & $\begin{array}{l}-0.108 \\
0.410\end{array}$ & $\begin{array}{c}0.509 \\
0.000 * *\end{array}$ & $\begin{array}{l}0.212 \\
0.104\end{array}$ \\
\hline $\begin{array}{l}\text { Lifetime } \\
\text { total }\end{array}$ & & & & & & & $\begin{array}{l}0.116 \\
0.378\end{array}$ & $\begin{array}{c}0.661 \\
<0.001 * *\end{array}$ & $\begin{array}{l}0.144 \\
0.271\end{array}$ & $\begin{array}{c}0.715 \\
<0.001 * *\end{array}$ \\
\hline $\begin{array}{c}\text { Past-year } \\
\text { HH }\end{array}$ & & & & & & & & $\begin{array}{l}0.139 \\
0.291\end{array}$ & $\begin{array}{l}-0.052 \\
0.695\end{array}$ & $\begin{array}{c}0.390 \\
0.002^{* *}\end{array}$ \\
\hline $\begin{array}{l}\text { Past-year } \\
\text { OCC }\end{array}$ & & & & & & & & & $\begin{array}{l}-0.170 \\
0.194\end{array}$ & $\begin{array}{c}0.785 \\
<0.001 * *\end{array}$ \\
\hline $\begin{array}{c}\text { Past-year } \\
\text { Rec }\end{array}$ & & & & & & & & & & $\begin{array}{c}0.366 \\
0.004^{* *}\end{array}$ \\
\hline
\end{tabular}

Notes: Bivariate correlations of physical fitness, body composition, and PA volume. ${ }^{* *}=$ indicates a significant value at the $p<0.01$ level; ${ }^{*}=$ indicates a significant value at the $p<0.05$ level: $\mathrm{BMI}=$ body mass index; $\mathrm{PA}=$ physical activity; $\mathrm{HH}=$ household PA; $\mathrm{Occ}=$ occupational $\mathrm{PA} ; \mathrm{Rec}=$ recreational $\mathrm{PA}$; total = total PA (sum of $\mathrm{HH}, \mathrm{Occ}$, and $\mathrm{Rec}$ ).

site. No significant differences between participants and nonparticipants were observed for age, Gleason, BMI or stage of disease (data not shown). All participants were measured for height and weight, and completed the LTPAQ interview, and baseline and follow-up questionnaires. Twenty-one participants were unable to attend the full baseline assessment and thus did not complete the fitness assessment and/or waist circumference measurement. In these cases, the LTPAQ was administered by phone and baseline and follow-up questionnaires were mailed and completed off-site. Of the 39 participants that attended the baseline appointment, 22 participants completed the aerobic fitness test.

Demographic and disease-specific information of participants are presented in Table 1. Physical activity, aerobic fitness and body composition data are presented in Table 2. Baseline and postoperative HRQOL and urinary symptom scores are presented in Table 3. The mean HRQOL change from baseline was +24.8 and statistically significant $(p<0.001)$, indicating a significant reduction compared to baseline. The mean change in urinary symptoms from baseline was +4.5 , also indicating a significant wors- ening of urinary symptoms $(p<0.001)$. Urinary symptoms and HRQOL were highly positively associated at baseline and follow-up $(r=0.49-0.55 ; p<0.001)$, as were the prepost surgery change scores $(r=0.56, p<0.001)$.

Pearson's $r$ correlations of PA volume, body composition and aerobic fitness are presented in Table 4. Lifetime and past-year PA (including subscales) were not significantly correlated with BMI or waist circumference. Only lifetime total PA was correlated with estimated $\mathrm{VO}_{2}$ max $(r=0.486, p=0.026)$, although moderate correlations between past-year PA and estimated $\mathrm{VO}_{2}$ max could not be ruled out due to small sample size $(r=0.369, p=0.155)$.

\section{Multiple linear regression}

The 2 models that included past-year PA demonstrated trends towards significance (i.e., $p<0.10$ ) in accounting for variance in HRQOL change from pre- to post-surgery. In the first model (Table 5), past-year PA significantly accounted for observed variance $(B=-0.063$, Beta $=-0.364, p=0.037)$ in a model that also included waist circumference and control variables 
Santa Mina et al.

Table 5. Regression coefficients for HROOL change: waist circumference and past-year PA

\begin{tabular}{|c|c|c|c|c|c|}
\hline \multirow{2}{*}{ Model } & \multicolumn{2}{|c|}{ Unstandardized coefficients } & \multirow{2}{*}{$\begin{array}{c}\text { Standardized coefficients } \\
\text { Beta }\end{array}$} & \multirow{2}{*}{$\mathbf{t}$} & \multirow{2}{*}{ Significance } \\
\hline & B & Standard error & & & \\
\hline Age & -0.353 & 0.433 & -0.142 & -0.814 & $P=0.422$ \\
\hline Time (surgery to follow-up) & 0.314 & 0.191 & 0.271 & 1.644 & $P=0.111$ \\
\hline Gleason score & 6.297 & 5.253 & 0.220 & 1.199 & $P=0.240$ \\
\hline Education & 6.455 & 4.639 & 0.227 & 1.391 & $P=0.174$ \\
\hline WC & -0.244 & 0.240 & -0.172 & -1.018 & $P=0.317$ \\
\hline Past-year PA & -0.063 & 0.029 & -0.364 & -2.183 & $\mathrm{P}=0.037^{*}$ \\
\hline
\end{tabular}

$\mathrm{PA}=$ physical activity; $\mathrm{WC}=$ waist circumference.

Notes: Multiple linear regression coefficients for the waist circumference, past-year PA and control model $(\mathrm{n}=39)$; Adjusted R2=0.156, $p=0.082 ;$ Dependent variable: $\Delta \mathrm{HROOL}$;

*indicates a significant value at $p<0.05 ; \mathrm{HRQOL}=$ health-related quality of life; PA = physician activity.

and, altogether yielded an adjusted $\mathrm{R}^{2}$ of $0.156(p=0.082)$ $(n=39)$. In the second model, past-year PA again accounted for significant variance $(\mathrm{B}=-0.063$, Beta $=-0.363, p=0.039)$ in a model that included BMI and control variables. Notably $\mathrm{BMI}$ did not account for significant variance $(\mathrm{B}=-0.296$, Beta $=$ $-0.072, p=0.681)$ and the entire model yielded an adjusted $\mathrm{R}^{2}$ of $0.141(p=0.099)$. Lifetime PA did not contribute to the variance observed in HRQOL change and models assessing urinary symptoms did not account for a significant amount of the variance (i.e., $p<0.10$ ). Estimated $\mathrm{VO}_{2}$ max and the control model were entered into multiple linear regression models with the HRQOL and urinary symptoms and also did not account for a significant proportion of variance in the outcome variable in the fitness-tested subsample $(n=22)$.

To further investigate the predictive ability of past-year PA in HRQOL change from baseline, Pearson correlations were conducted for each subtype of PA activity (occupational PA, household PA, recreational PA) with past-year PA. Bivariate associations with past-year PA were: household PA $(r=0.390, p=0.002)$, occupational PA $(r=0.785, p<0.001)$ and recreational PA $(r=0.336, p=0.004)$. Subsequently, each type of activity was individually entered into a hierarchical multiple linear regression model with identical control variables. Only the model with past-year occupational PA demonstrated a significant adjusted $R^{2}\left(R^{2}=0.12 ; p=0.040\right)$ and occupational PA independently contributed to the HRQOL variance observed $(\mathrm{B}=-0.057$, Beta $=-0.243 ; p=0.089)$.

\section{Discussion}

This study appears to be the first one to assess the effects of PA on HRQOL outcomes after PCa patients undergo RP. The results indicate that higher past-year PA levels are associated with lesser reductions in HRQOL in the month following RP. The observed effects of past-year PA, specifically occupational PA, should motivate further investigation into the measurement of PA in the year prior to RP.

Neither BMI nor waist circumference independently accounted for significant amounts of variance in preoperative to postoperative changes in HRQOL or urinary symptoms. Other studies examining the psychosocial impact of obesity on postoperative outcomes, specifically HRQOL outcomes, have provided inconsistent findings regarding body composition. ${ }^{21-24}$ Our results suggest that when combined with past-year PA, waist circumference is slightly better than $\mathrm{BMI}$ in predicting HRQOL reductions following RP.

This was also the first study to employ the LTPAQ in PCa patients undergoing treatment and to demonstrate the feasibility of this assessment tool in clinical populations. Interestingly, neither lifetime PA nor past-year PA (or their sub-categories) were correlated with BMI or waist circumference, which suggests some validity challenges when this instrument is interpreted as a proxy for body composition. Although $\mathrm{VO}_{2}$ max was significantly correlated with lifetime total PA, it was not correlated with past-year PA volumes. As a proxy measure of physical fitness, the LTPAQ therefore requires further validation.

\section{Limitations}

Study results were limited by the small sample size and reduced statistical power. Because assessments of waist circumference and aerobic fitness were only obtained on a sub-sample, the sample sizes for these measures were also too small for inclusion in larger models. A post-hoc sample size calculation using this pilot data and the $\mathrm{R}^{2}$ of the marginally significant models examining HRQOL change indicated that a sample of 58 would be required to yield a power of 0.8 and an alpha of 0.05 for past-year PA and waist circumference; a sample of 171 would be required to yield identical power and alpha for past-year PA and $\mathrm{BMI}$. In the absence of greater power, the clinical significance of present findings must be cautiously interpreted. However, marginally significant findings with small samples typically warrant additional investigations with greater power to confirm findings. Finally, with respect to sam- 
pling, selection bias might have resulted in more physically active participants who were more willing to participate in a PA interview and fitness assessment than those who were sedentary. Even though BMl is a crude measure of physical fitness, it did not differ between participants and non-participants, which suggests a mitigation of selection bias.

Second, the postoperative follow-up of about 4 weeks is brief and more meaningful differences in symptom resolution related to PA could be detectable with longer follow-ups. Given that HRQOL and urinary symptoms can take up to 2 years to return to baseline, a long-term, serial follow-up plan would be optimal.

Third, interpretation of PA measured via self-report measure is vulnerable to response and recall bias. The LTPAQ is a new tool that estimates lifetime PA volume using cognitive interviewing methods designed to enhance recall and accuracy. Although lifetime PA was related to $\mathrm{VO}_{2}$ max, the sample size was insufficient to draw definitive conclusions regarding validity. Additional objective measures of PA to corroborate self-report (e.g., pedometer or accelerometer) are appropriate. The usage of a sub-maximal, indirect assessment of aerobic fitness that employs a heart rate response to exertion proved problematic due to the prevalence of patients taking antihypertensive medications that blunt the heart rate responses to exercise. A more robust, direct assessment of $\mathrm{VO}_{2}$ max or functional capacity test is recommended for similar populations.

Fourth, waist circumference was not available for all subjects, as this is not a part of standard preoperative assessment; several participants were unable to schedule an additional visit to the hospital for this measurement. Waist circumference could be incorporated as a regularly collected measure in RP patients in prostate clinics in the future.

\section{Future directions}

Study results support the hypothesis that a preoperative intervention for RP patients could offset some of the acute decline in HRQOL following surgery. This hypothesis should be examined using an experimental design with appropriate controls to evaluate the effectiveness of "prehabilitation" (preoperative exercise intervention) on clinical outcomes related to RP such as surgical margins, nerve-sparing status and surgical complications - all of which can lead to side effects relevant to HRQOL decline. Prehabilitation has demonstrated benefits in major abdominal surgery and thoracic surgery for lung cancer. ${ }^{11,25,26,27}$ Given the potential time available between diagnosis of cancer and surgery for many cancers, prehabilitation research is warranted in clinical cohorts, particularly when the current study and previous research demonstrate a potential protective HRQOL effect. Furthermore, waist circumference is generally accepted as a more robust meas- ure of adiposity than BMI and represents an easy and potentially powerful measure that may be regularly employed, preoperatively, to predict postoperative HRQOL outcomes. Finally, future studies should employ a measure of urinary incontinence given the high prevalence of this side effect in the weeks following surgery and its HRQOL associations.

\section{Conclusion}

Past-year PA, specifically occupational PA, appears to reduce the negative HRQOL impact typically seen in PCa patients undergoing RP about 30 days post-surgery. Additional studies should further clarify the role of PA on RP outcomes for PCa and the validity of the LTPAQ as a proxy measure for overall physical fitness.

*Department of Surgical Oncology, Princess Margaret Hospital, Toronto, ON; 'Division of Clinical Decision-Making \& Health Care, Toronto General Hospital, Toronto General Research Institute, Toronto, ON; ₹School of Kinesiology and Health Science, York University, Toronto, ON

Acknowledgements: We acknowledge the great contributions in patient recruitment, data acquisition, and consultation by Dr. Neil Fleshner, Dr. Antonio Finelli, Dr. Michael Jewett, Dr. Alexandre Zlotta, Dr. Joel Katz, Jennifer Harris RN, Leah Jamnicky RN, Kristen Currie, Michael Nesbitt, and all of the nurses and volunteers at the Prostate Centre in the Princess Margaret Hospital.

Competing interests: Funding for this study was provided by the University Health Network Trainee Award in Prostate Cancer Research and Princess Margaret Hospital Prostate Centre Research Fund, Toronto, $\mathrm{ON}$.

This paper has been peer-reviewed.

\section{References}

1. American Cancer Society. Cancer facts \& figures 2008. 2008;1-72.

2. Canadian Cancer Society/National Cancer Institute of Canada. Canadian cancer statistics. 2008;1-72.

3. Hsing AW, Tsao L, Devesa SS. International trends and patterns of prostate cancer incidence and mortality. Int I Cancer 1999;85:60-7.

4. National Comprehensive Cancer Network. NCCN clinical practice guidelines in oncology: Prostate cancer. 2008; 1:1-44.

5. Quinn $M, B a b b P$. Patterns and trends in prostate cancer incidence, survival, prevalence and mortality. part I: International comparisons. BJU Int 2002;90:162-73.

6. Ficarra $V$, Novara $G$, Galfano $A$, et al. Twelve-month self-reported quality of life after retropubic radical prostatectomy: A prospective study with rand 36-item health survey (Short Form-36). BJU Int 2005;97:274-8.

7. Culos-Reed SN, Robinson JL, Lau H, et al. Benefits of a physical activity intervention for men with prostate cancer. J Sport Exerc Psychol 2007;29:118-27.

8. Monga U, Garber SL, Thornby J, et al. Exercise prevents fatigue and improves quality of life in prostate cancer patients undergoing radiotherapy. Arch Phys Med Rehabil 2007;88:1416-22.

9. Segal RJ, Reid RD, Courneya KS, et al. Randomized controlled trial of resistance or aerobic exercise in men receiving radiation therapy for prostate cancer. J Clin Oncol 2009;27:344-51.

10. Segal RJ, Reid RD, Courneya KS, et al. Resistance exercise in men receiving androgen deprivation therapy for prostate cancer. J Clin Oncol 2003;21:1653-9.

11. Carli F, Zavorsky GS. Optimizing functional exercise capacity in the elderly surgical population. Curr Opin Clin Nutr Metab Care 2005;8:23-32.

12. Friedenreich CM, Courneya KS, Bryant HE. The lifetime total physical activity questionnaire: Development and reliability. Med Sci Sports Exerc 1998;30:266-74. 
Santa Mina et al.

13. Ainsworth BE, Haskell WL, Whitt MC, et al. Compendium of physical activities: An update of activity codes and MET intensities. Med Sci Sports Exerc 2000;32(9Suppl):S498-504.

14. The Canadian Physical Activity, Fitness \& Lifestyle Approach (CPAFLA): CSEP- Health \& Fitness Program's health-Related Appraisal and Counselling Strategy (3rd Ed.) Ottawa: CSEP; 2003.

15. Weller IM, Thomas SG, Corey PN, et al. Prediction of maximal oxygen uptake from a modified Canadian aerobic fitness test. Can J App Physiol 1993;18:175-88

16. Weller $I M$, Thomas $S G$, Gledhill $N$, et al. A study to validate the modified Canadian aerobic fitness test. J App Physiol 1995;20:211-21.

17. Krahn M, Ritvo P, Irvine J, et al. Construction of the patient-oriented prostate utility scale (PORPUS): A multiantribute health state classification system for prostate cancer. J Clin Epidemiol 2000;53:920-30.

18. Ritvo P, Irvine J, Naglie $G$, et al. Reliability and validity of the porpus, a combined psychometric and utility-based quality-of-life instrument for prostate cancer. J Clin Epidemiol 2005;58:466-74.

19. Barry MJ, Fowler FJ, O'Leary MP, et al. The American Urological Association symptom index for benign prostatic hyperplasia. J Urol 1992;148:1549-57.

20. Gray M. Psychometric evaluation of the international prostate symptom score. Urol Nurs 1998; 18:175-83.

21. Chang SS, Duong DT, Wells N, et al. Predicting blood loss and transfusion requirements during radical prostatectomy: The significant negative impact of increasing body mass index. J Urol. 2004;171:1861-5.
22. Anast JW, Sadetsky N, Pasta DJ, et al. Impact of obesity on prostate cancer on health-related quality of life before and after radical prostatectomy: Data from CaPSURE. J Urol 2005;66:1060-5.

23. Freedland SJ, Haffner MC, Landis PK, et al. Obesity does not adversely affect health-related quality-oflife outcomes after anatomic retropubic radical prostatectomy. Urology 2005;65:1131-6.

24. Montgomery JS, Gayed BA, Hollenbeck BK, et al. Obesity adversely affects health related quality of life before and after radical retropubic prostatectomy. J Urol 2006;176:257-61

25. Cook JW, Pierson LM, Herbert WG, et al. The influence of patient strength, aerobic capacity and body composition upon outcomes after coronary artery bypass graffing. Thorac Cardiovasc Surg 2001;49:89-93.

26. Jones $\mathrm{LW}$, Peddle $\mathrm{CJ}$, Eves ND, et al. Effects of presurgical exercise training on cardiorespiratory fitness among patients undergoing thoracic surgery for malignant lung lesions. Cancer 2007;1 10:590-8.

27. Peddle $\mathrm{CJ}$, Jones $\mathrm{LW}$, Eves ND, et al. Effects of presurgical exercise training on quality of life in patients undergoing lung resection for suspected malignancy. Cancer Nurs 2009;32:158-65.

Correspondence: Mr. Daniel Santa Mina, The Prostate Centre, 4-911, Princess Margaret Hospital, 620 University Ave., Toronto, ON M5G 2M9; Daniel.Sta.Mina@uhn.on.ca 